\title{
Preexposure to the UCS affects avoidance conditioning
}

\author{
RICHARD T. BROWNING and WALTER ISAAC \\ University of Georgia, Athens, Georgia
}

\begin{abstract}
Four groups of hooded rats received 100 trials of avoidance training per day for 10 days in a four-way shuttlebox. The animals were assigned to experimental groups as follows: Group 1 received 25 escape trials immediately preceding avoidance training on Day 1 . Group 2 were placed in the chamber on Day 1 for the equivalent time required for escape pretraining. Group 3 animals were exposed to the 25 escape trials on the day preceding the beginning of avoidance training. Group 4 received avoidance training only. All groups acquired the avoidance response to a similar level in the first two sessions. Significant group effects $[F(3,20)=14.36, p<.01]$ were seen, with the performance of Group 1 decreasing on Day 3 and remaining lower over the 10 days of the experiment. Thus, a delayed long-term interference effect was found when escape pretraining immediately preceded avoidance training.
\end{abstract}

The effects of preexposure to electrical shock upon avoidance learning are not simple. In previous studies using pretreatments of inescapable or escapable shock, inescapable shock groups have been found unable to develop an escape response. Such "learned helplessness" has been demonstrated in both dogs (Overmier \& Seligman, 1967; Seligman \& Maier, 1967) and rats (Seligman \& Beagley, 1975). The effect has been seen to dissipate after a 48-h period (Overmier \& Seligman, 1967), and it is thought to be due to a disruption in central nervous system monoamine activity (Weiss, Glazer, \& Pohorecky, 1976).

A second type of interference has been found to persist after 7 days in inescapably shocked animals. This effect is thought to be learned, due to its persistence over time (Glazer \& Weiss, 1976a, 1976b).

Studies using escapable shock have reported less consistent effects. Lord, King, and Pfister (1976) proposed that different mechanisms were involved in escape and avoidance behavior in rats given chronic peripheral sympathectomy, since escape, but not avoidance behavior, was affected adversely. Mowrer and Lamoreaux (1946) had found evidence that avoidance responses are more easily learned when they are similar to escape responses than when the two required responses differ. However, Bolles (1969) found the primary requirement for rapid acquisition of an avoidance response to be its similarity to the animal's natural defense reactions. He also found that the avoidance response is not always facilitated when escape and avoidance behaviors are identical.

In the present study, pretraining of an escape response identical to the avoidance response was hypothesized to result in a positive transfer to later avoidance training,

The authors are grateful to W. B. Pavlik for his suggestions in the preparation of this manuscript. Correspondence may be addressed to Walter Isaac, Department of Psychology, University of Georgia, Athens, Georgia 30602. facilitating this response. Also of interest were the longterm effects of this type of pretraining.

\section{METHOD}

Subjects

The subjects were 24 Long-Evans-derived rats 100-110 days old at the start of the experiment. These animals were individually housed and received food and water ad lib in their home cage throughout the study. The animals were kept on a 12:12-h light:dark cycle (on 6:00 a.m., off 6:00 p.m.). Half of each group were run in the a.m. (7:30 a.m. till 11:30 a.m.), and half in the p.m. (12:30 p.m. till 5:30 p.m.).

\section{Apparatus}

A shuttlebox similar to that first described by Meyer, Isaac, and Maher (1958), measuring $61 \times 61 \mathrm{~cm}$, with hurdles $5 \mathrm{~cm}$ high dividing the box into four equal quadrants, was used for both escape training and avoidance conditioning. The grid floor and the hurdle tops could be electrified $(990 \mathrm{~mW})$. A removable glass top $15 \mathrm{~cm}$ above the floor allowed viewing and transfer of the animals.

Continuous background lighting ( $<5 \mathrm{fc}$ ) was provided by a 15 -W bulb in a reflective fixture facing the ceiling of the experimental room. The ambient sound level was $60 \mathrm{~dB}$ SPL (C scale) at the floor of the chamber. A doorbuzzer ( $85 \mathrm{~dB} \mathrm{C}$ scale, at chamber floor) was mounted above the chamber top. A 200 -W bulb for the CS was located $20 \mathrm{~cm}$ above the floor of the chamber. This additional lamp provided $210 \mathrm{fc}$ at the floor and served as the CS. This apparatus and the following conditioning procedures have been used in our lab for many years (Gavin \& Isaac, 1986; Isaac, 1964; Worthington \& Isaac, 1967).

\section{Procedure}

All animals were given 100 avoidance conditioning trials per day for 10 days. Prior to each conditioning session, each subject was allowed a 5-min exploration period in the chamber. The trials began when the 200-W bulb above the shuttlebox was turned on. After a 4-sec period, the grid was electrified and the buzzer activated if the rat did not move from one quadrant of the box to any other. The CS was terminated if the subject completed the avoidance response in this period. If the response was not completed, both the CS and the UCS continued until the animal crossed a hurdle to a different quadrant. All the animals learned to cross the barrier to escape the compound UCS. The trials were presented on a VI 30-sec schedule with a range of 20 to $40 \mathrm{sec}$. Each animal was given a rest period of $10 \mathrm{~min}$ on completion of each session, before removal to the home cage. 
Four groups of 6 rats each were randomly assigned to different conditions of training, as follows: Group 1 received 25 escape trials on the day avoidance training began, immediately preceding the 100 avoidance conditioning trials. Group 2 spent an equivalent time in the box preceding the avoidance conditioning trials on the day avoidance training began, as did Group 1, but no escape training trials were given. Group 3 received 25 escape training trials on the day preceding the day avoidance training began. Group 4 received no escape training and avoidance conditioning began immediately after the 5 -min habituation period. The escape trials were also presented on a VI 30 -sec schedule. They were identical to the avoidance trials, in the shock parameters used and the response required for termination. The UCS in escape training also consisted of the combination footshock and doorbuzzer. No CS was presented, however.

\section{RESULTS}

The mean numbers of avoidance responses for the four groups of male rats over the 10 avoidance conditioning sessions are presented in Figure 1. As can be seen, all groups acquired the response to a similar level in the first two sessions. An analysis of variance was used to compare the overall performance of groups under the four training procedures. Differences in overall performance were significant $[F(3,20)=14.36, p<.01]$. The decrement in Group 1 scores began on Day 3, and daily scores remained lower throughout the experiment. Performance difference over days was found to differ significantly $[F(9,180)=8.13, p<.01]$. It can be seen that all groups except for the one given immediate UCS preexposure (Group 1) remained at a consistent level of avoidance. Tests on mean group scores showed Group 1 to be significantly lower overall compared with the other groups (Duncan's multiple range, $p<.01]$.

\section{DISCUSSION}

In neither short-term (Overmier \& Seligman, 1967; Seligman \& Maier, 1967) nor long-term (Glazer \& Weiss, 1976a, 1976b) studies using inescapable shock have the conditioning effects been similar to those in the present study, which would indicate a different effect operating here. Seligman and Maier (1967) found no interference with escape/avoidance

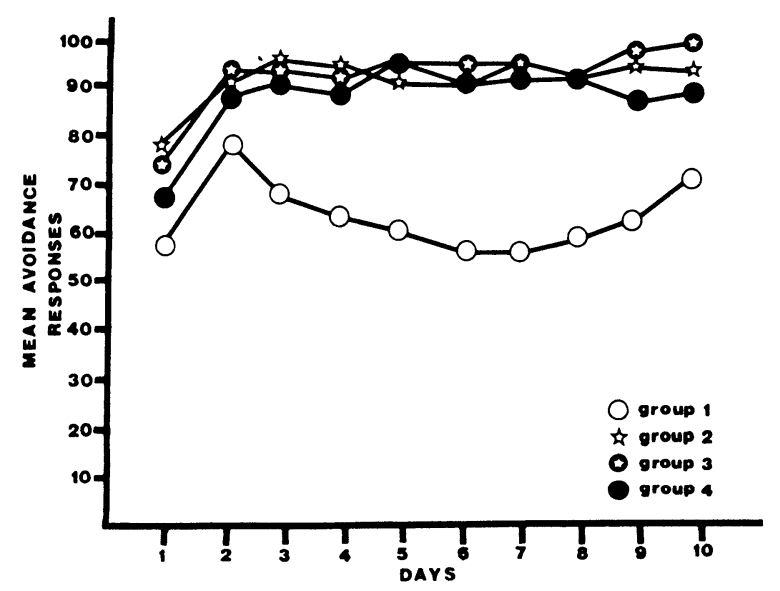

Figure 1. Mean avoidance responses over days. conditioning when escapable shock preceded this conditioning by $24 \mathrm{~h}$. This finding is supported by the present study, in which escape pretraining $24 \mathrm{~h}$ earlier produced no interference for later avoidance conditioning (Group 3). The present effect was of lesser severity, however, since all the animals presented some avoidance responding throughout the experiment. The present effect also differed in time of onset, for the deficit was not seen in immediately preexposed rats (Group 1) until the third day. Group 1 was then seen to decrease avoidance responses as the sessions continued, stabilizing at a much lower level than the other groups. This effect cannot be seen as an extinction of avoidance behavior, because some level of avoidance was maintained by all the animals.

This UCS preexposure effect with escape pretraining was found to produce enduring effects, with some defining parameters. Immediate escape pretraining (Group 1) produced the effect, whereas a 24-h period between the UCS pretraining and avoidance training did not (Group 3). Thus, the delay in the time between pretraining and subsequent avoidance training prevented the effect. The effect did not result from preexposure to the apparatus immediately before the first avoidance conditioning session (Group 2), because this group performed as well as the animals that received avoidance training only (Group 4). While preexposure to the UCS has been studied primarily with inescapable shock, less attention has been focused on escapable shock; further study of this delayed and long-lasting effect is warranted.

\section{REFERENCES}

Bolles, R. C. (1969). Avoidance and escape learning: Simultaneous acquisition of different responses. Journal of Comparative \& Physiological Psychology, 68, 355-358.

GAvIN, M. R., \& ISAAC, W. (1986). Recovery of function of a conditioned avoidance response in rats with serial and single stage bilateral occipital ablation. Physiological Psychology, 14, 31-35.

GlaZER, H. I., \& WeISS, J. M. (1976a). Long-term interference effect: An alternative to "learned helplessness." Journal of Experimental Psychology: Animal Behavior Processes, 2, 202-213.

Glazer, H. I., \& Weiss, J. M. (1976b). Long-term and transitory interference effects. Journal of Experimental Psychology: Animal Behavior Processes, 2, 191-201.

IsAAC, W. (1964). Role of stimulation and time in the effects of spaced occipital ablations. Psychological Reports, 14, 151-154.

LoRD, B. J., KING, M. G., \& Pfister, H. P. (1976). Chemical sympathectomy and two-way escape and avoidance learning in the rat. Journal of Comparative \& Physiological Psychology, 90, 303-316.

Meyer, D. R., IsAAC, W., \& MAHER, B. A. (1958). The role of stimulation in spontaneous reorganization of visual habits. Journal of Comparative \& Physiological Psychology, 51, 546-548.

MoWrer, O. H., \& LAmOREAUX, R. R. (1946). Fear as an intervening variable in avoidance conditioning. Journal of Comparative \& Physiological Psychology, 39, 29-50.

Overmier, J. B., \& Seligman, M. E. P. (1967). Effects of inescapable shock upon subsequent escape and avoidance learning. Journal of Comparative \& Physiological Psychology, 63, 28-33.

Seligman, M. E. P., \& Beagley, G. (1975). Learned helplessness in the rat. Journal of Comparative \& Physiological Psychology, 88 , 534-541.

Seligman, M. E. P., \& Maier, S. F. (1967). Failure to escape traumatic shock. Journal of Experimental Psychology, 74, 1-9.

Weiss, J. M., Glazer, H. I., \& Pohorecky, L. A. (1976). Coping behavior and neurochemical changes: An alternative explanation for the original "learned helplessness" experiments. In G. Serban and A. Kling (Eds.), Animal models in human psychobiology (pp.141-173). New York: Plenum Press.

WORTHINGTON, C. S., \& ISAAC, W. (1967). Occipital ablation and retention of a visual conditioned avoidance response in the rat. Psychonomic Science, 8, 289-290. 